\title{
Matt Barlow
}

\section{Enchanted Bee-ings: Encounters and Movements beyond the Human}

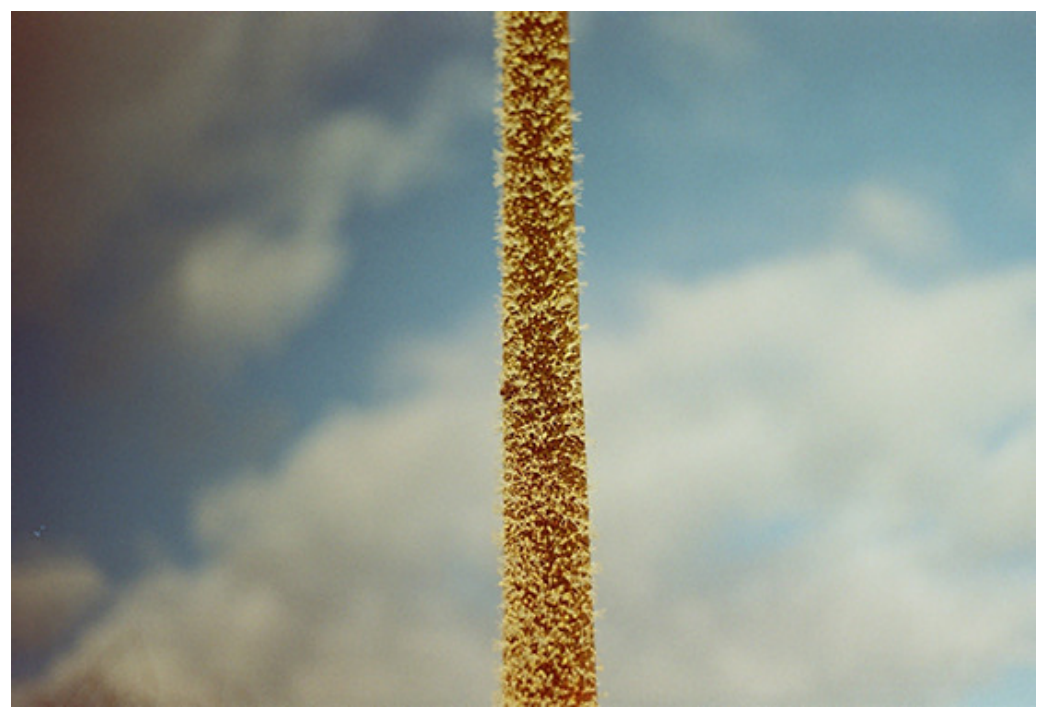

Xanthorrhoea [yucca] \& honeybee, South Australia, 2014 (image by author).

We can feel that their march across the landscape is intentional.

We cannot deny; they are going to a place they have in mind.

That's where we're headed now. - Carl Safina (Beyond Words 8)

Encounters with enchantment. Honeybees (apis millefera - henceforth, simply "bees") have maintained a mystical, symbolic, and material presence in human imaginations and livelihoods for millennia. Whether as representations carved atop ancient Egyptian tombs, cave drawings of ancient honey hunters in Australia, or references to bees in the Bible and the Koran, material evidence suggests that bees have played a significant role in the lives of humans since the beginnings of history. ${ }^{1}$ A voluminous literature details the behavioral and physiological patterns of the honeybee (Lindauer), the development of global apiculture (Jakobsen), and the historical and contemporary uses of bees in warfare (Lockwood). Absent from these discussions is a recognition of the affective and inspirational relationships that continue to emerge between humans and bees. It is this absence that this paper seeks to remedy. It does so by working through a contemporary model of enchantment explicated by political theorist Jane Bennett. Using enchantment as a kind of theoretical (and ontological) anchor, I wish to investigate different ways of 
knowing bees, moving (with) bees, entangling with bees, and eventually arriving at an anthropology of being with bees, an anthropology of "bee-ing." It is a story that speaks to science, history, agriculture, environments, ecologies, politics, and technologies; a story concerned with touch, taste, sound, love, fear, "hope in blasted landscapes" (Kirksey, et al. 29), "dreams and nightmares" (Raffles 3). It is a response to the realization that, despite the odds, a particular kind of flourishing between humans and bees continues to erupt amid the kaleidoscope of contemporary lives.

Enchantment, as Bennett presents it and as I wish to use it, is when "a condition of exhilaration or acute sensory activity" induces a feeling of being "simultaneously transfixed in wonder and transported by sense, to be both caught up and carried away" (Enchantment 5). The word enchantment derives from the French verb chanter, to sing, and lends itself to the way bees "cast a spell with sounds," so that, once one becomes attuned, the sound of the hive "moves like water around and inside your ears," acting as an organic white noise machine that "stimulates, calms, or soothes you" (Moore \& Kosut 95-96). Bennett specifically cites "the discovery of sophisticated modes of communication among non-humans" and being "struck and shaken by the extraordinary that lives amid the familiar and the everyday" as junctures likely to induce moments of enchantment (op. cit., 4). Employing this model of enchantment will, I argue, enable me to unpack the ethereal inter-species encounters that emerge between humans and bees, and to aid in articulating an anthropology that moves beyond the human.

The power that bees have over humans is evident from the many books that deal with encounters between them. It involves passion and efficacy that moves beyond scientific or journalistic commentary. Beekeepers and scientists alike describe being overwhelmed by what Moore and Kosut have termed the "affective buzz" of being with bees (88). Karl von Frisch, a father of ethology and author of The Dancing Bees (1927/1954), described this as falling "irresistibly under the spell of the honey-bee" (Raffles 174); half a century later, urban bee-keeper Meg Paksa similarly declares her "immediate reverence for what goes on in the hive" (Moore \& Kosut 104). By analyzing these encounters and others like them, and how these encounters have changed over time, I hope to render enchantment palpable as a useful way of comprehending efficacious inter-species encounters. I do this in defense of a world that has "become neither inert nor devoid of surprise but continues to inspire deep and meaningful attachments" (Bennett 4). These attachments work in opposition to tales of disenchantment in which modern life - from the turn of the 19th century until the present - is increasingly characterized by an "alienated existence on a dead planet." Ultimately, I hope to move, following Phillippe Descola, "beyond nature and culture," 
toward an anthropology that finds joyous encounters between species just as analytically enticing, and theoretically rich, as disastrous ones.

Knowing (without knowing) bees. One of the first modern writers to describe enchantment with bees was the poet, playwright, and amateur biologist Maurice Maeterlinck, whose The Life of the Bee (1901) portrays how "the image of the beehive conjures orderliness, virtue, peacefulness and a pervasive honeyed sweetness," which he likened to a childhood sense of wonder at the world (Mathews 159). Maeterlinck was particularly enchanted by the ability of the bees to make collective decisions, the greatest of which, in his eyes, was the seemingly spontaneous decision to swarm. Maeterlinck called this "the spirit of the hive." He noticed that a bee colony would leave its hive when it was at its zenith, when stocks were at their highest, the pollen at its most tempting, and the brood at its healthiest. To recognize this was to realize that perhaps humans could learn something from bees about becoming better stewards of Earth and its inhabitants:

Where is the fatality here, save in the love of the race of to-day for the race of to-morrow? This fatality exists in the human species also, but its extent and power seem infinitely less. Among men it never gives rise to sacrifices as great, as unanimous, or as complete. What far-seeing fatality, taking the place of this one, do we ourselves obey? We know not; as we know not the being who watches us as we watch the bees. (47)

Maeterlinck proposed that in the presence of bees, humans are "confronted by the enigma of intellect, of destiny, will, aim, means, and causes; by the incomprehensible organisation of the most insignificant act of life" (38). Becoming enchanted by bees was, for him, a realization and a recognition that bees had a form of collective agency, that they acted in particular ways for particular ends, which he could not fully comprehend. Learning more about how bees went about their lives left Maeterlinck with more questions than answers about both bees and his own place in the world as a human being co-existing with them. This challenged the "fantasy of human exceptionalism" dominant in Europe at the turn of the 20th century, as well as "the great divides of animal/human, nature/culture, organic/technical, and wild/domestic" that modern science hinged upon (Haraway 11, 15). A generation later prominent ethologist and fellow Nobel laureate Karl von Frisch documented a similar enchantment with honeybees in his magnum opus, The Dancing Bees.

Humanimalia: a journal of human/animal interface studies

Volume 8, Number 2 (Spring 2017) 
Through numerous experiments "of exceptional elegance" von Frisch's work established that bees possess language, "the capacity long definitive of humanity" (Raffles 171). He did so by demonstrating that individual bees were able to communicate non-symbolically, using experience and memory to convey to the rest of the colony the direction, distance, and quality of a food source. Von Frisch noticed that returning foragers would perform repeated movements in the hive that attracted the attention of the other bees. To account for this phenomenon, he explored how the bees were conveying information to each other; that is to say, he was primarily concerned with semiotics. He found that the bees were dancing, and that this dancing conveyed complex information to the rest of the hive. A brief digression here into the language of the honeybee may be valuable for understanding the complexity of the enchantment von Frisch felt for his bees.

Essentially, von Frisch saw that the foraging bee, upon returning to the hive, performs her $^{2}$ "dance" on the landing pad of the hive (von Frisch called it "the dance floor") by vigorously wagging her abdomen while walking in the direction of the food source. She then moves into the darkness of the hive and reconfigures "the indexical association between the dance floor and the food source," in order to perform the same dance on the vertical wall of the hive (Raffles 180). To do this, she recalls the direction of the sun in relation to the food source on the outbound flight, and transposes that to an angle that relates to gravity, also accounting for the movement of the sun during the time it has taken to return from the food source. The bees in the hive not only know immediately the direction of the food source, but are also able to identify the type of flower through the scent of the returning forager, and the quality of the nectar from the taste of the pollen on its skin. Astonishingly, by recognizing patterns of polarized light invisible to humans, all this is accomplished even when the sun is obscured by clouds.

Von Frisch's research revolutionized ethology and extended human understanding of insects to include those small agencies that reside in the actions of bees. Small agencies, as Bennett, drawing on Darwin, describes them, are those seemingly insignificant actions such as pollination (by bees) and fertilization (by worms) that leave lasting effects on other life around them, and are examples of the complex ways in which life on Earth depends upon co-existence and mutual flourishing (Vibrant 94). Von Frisch's discoveries stood in opposition to many dominant theories in animals studies of the early to mid-twentieth century, which generally reduced animal communication to "simple stimulus responses, such as reflexes and tropisms" (Raffles 178).

Von Frisch's conclusions do not suggest that honeybees are somehow like humans, that we exist in and understand the world in similar ways, but rather that "the honeybees' 
repertoire exceeds functional explanation and biochemical predictability," and as such shifts scientific discovery beyond the "metaphor of the machine" (Raffles 198). In understanding how complex creatures like bees communicate, for instance, humans are faced with increasingly important decisions as to how to go about reconfiguring the nature of their relationships with them outside theology and the dominant binaries of nature/culture, human/nonhuman. As Bennett proposes, complex modes of communication found in non-humans challenge common ideas of what it means to be human, and can render attachments between species more palpable and audible (Enchantment 4). These discoveries help break down the notion that humans are at the top of the so-called "animal kingdom." They also invite further investigations into how other animals are different from humans, recognizing that they have distinct modes of operating in the world that are often beyond explicit human comprehension. As such, they provide us with enchanting encounters that remain within scientific, secular modes of thought that emerge within a scientific and technological framework.

A number of recent ethnographies aim to give life to these affective ways of learning from animals, plants, and other sentient beings (cf. Kohn; Kimmerer; Cruikshank; De la Cadena), and becoming attuned to different approaches to understanding the ways in which human and non-human beings exist in the world. Affective enchantment was the medium through which Maeterlinck and Von Frisch came to believe that humans are not exceptional, but part of a collective of species that together bring the planet into existence, and that when humans pay sufficiently close attention to such cross-species encounters, they will learn a great deal about others and themselves. Enchantment is one mode of becoming attuned to these agencies, requiring a recognition of nonsymbolic forms of communication among species. Unfortunately, despite the efforts of those like Maeterlinck and von Frisch, honeybees (along with most other insects) have continued to occupy a "relative blind spot in our moral and cultural, even our ecological, imaginations" (Mathews 160). It was not until bees began to disappear in unprecedented numbers in 2006 that modern humans were challenged to change their attitudes toward them and their environment. It was through catastrophe, not discovery, that it became the "insects' turn to come into focus."

Movements. Although bee populations have gone through periods of decline and regeneration over the last century, what began to occur in North America around the beginning of the 21st century was on many accounts unprecedented (Kosek 650). Bees were not just dying, they were disappearing, seemingly without a trace, in epic proportions. This cataclysm became known as CCD, or Colony Collapse Disorder, and it focused attention on the honeybee as never before. There is no single cause for CCD,

Humanimalia: a journal of human/animal interface studies

Volume 8, Number 2 (Spring 2017) 
but rather an accumulation of viruses, parasites, poor breeding practices, exhaustive commercial migratory pollination routes, and increasingly volatile weather patterns that have together contributed to the phenomenon (Nimmo). Addressing the issue has been more difficult than anticipated, and today bee populations in the agricultural industry remain at risk. CCD has moved bees into "the realm of animal politics, at the intersections among environmental issues and the politics of food production" (Moore \& Kosut 48). People have become urgently interested in the well-being of the bee, and have begun to see bees not merely as potentially harmful pests, but as animals whose crucial role as pollinators and sources of inspiration is integral to the future (as it is to the history) not only of the human species, but of life on Earth.

This symbolic shift is mirrored by a material one, whereby bees are now welcomed into cities in an attempt to provide them refuge. Yet cities, almost by definition, are human spaces. They are filled with the buzz of human activity, a steady hum that reminds us of the things humans do with the things they have created, and which often exemplify the separation between wild and domestic space.

Domesticity can be defined in this sense as synonymous with "tame" - to be kept by humans in a private setting in an existence characterized by discipline and restraint. Something that is deemed "wild" can be understood as an organism in an environment that is not domesticated or cultivated - a concept often assumed to be synonymous with uncivilized and primitive, uncontrolled, and, in a sense, free. In proposing the separation between wild and domestic as a precursor to other dualisms such as nature and culture, urban and rural, anthropologist Phillipe Descola helps us to understand how the convergence of bees and humans in urban, domestic settings such as cities challenges our neat definitions of such terms. As Anna Tsing states, "it is this tension between their domestic embodiments and refusals that makes honeybees interesting as creatures of nature; they defy human control even as they exemplify domesticity" (120). When bees move into cities, either of their own volition or that of humans, they force their human counterparts to let go of full control of the situation and to work with bees on their terms, to synchronize with their biological and behavioral patterns of production and reproduction. By welcoming bees into cities, they are re-defining the categories constructed to separate human from non-human life. The collapse of the honeybee as an agricultural tool comes at a time when the meanings of terms such as wild, domestic, urban, rural, natural, and cultural, appear to be dissolving, leaving in their wake something more like an assemblage ${ }^{3}$ of humans and non-humans "striving to coexist in common worlds" (Moore \& Kosut 89). 
Exploring the phenomenology of beekeeping in an urban context, and the motivations of this new breed of beekeepers in New York, Lisa Jean Moore and Mary Kosut discovered a "pleasantly motley crew of people, embodying different personal styles, political perspectives, and manners of beekeeping" (Buzz 3). They had to overcome many methodological difficulties in their research, including how to write ethnographically about relationships between insects and humans, and to conduct participant observation across both species. They began by enrolling in an introductory beekeeping course led by urban beekeeping enthusiast Jim Fischer. The classroom itself presented practical and professional challenges; Moore and Kosut found they were "simultaneously taking notes about bees combined with learning how to be a beekeeper, while also attempting a sociological meta-level analysis of who was in the room and thinking about their concerns and connections to other humans and European honeybees" (4). Once they had the skills of novice beekeepers, and had discovered a sense of "bee fear as well as bee love" (5), Moore and Kosut established beehives in a local college and attended lectures about urban beekeeping at DIY educational collectives around the Brooklyn area. In the course of their three-year research, they interviewed more than thirty urban beekeepers with varied experience, performed hive inspections at numerous locations, and attended special bee events throughout New York. As an "api-ethnography," their book Buzz engages bees as informants, with the aim of learning "from consorting with the bees themselves" (36).

Moore \& Kosut's ethnography reveals that bees, humans, and the matter of contemporary urban life become entangled with unusual vitality in new places "made meaningful over time because [they are] embodied, lived in" (22). In the wake of CCD, urban beekeeping has emerged as a cultural practice marked by "the marvellous erupting amid the everyday" (Bennett 8 ), in which bees find refuge from the harmful agricultural practices that seem to be decimating their populations, and where humans can escape the stress of inner-city living. Together, humans and bees have adopted new urban sensibilities that could transform urban spaces into places made meaningful through their shared experiences. For the humans, these experiences are suffused with feelings of enchantment, wonder, and awe.

The movement of honeybees into the urban landscape in the wake of cataclysm provides a fine example of how "space is transformed into place as it acquires definition and meaning" (Tuan 136). Moore \& Kosut's ethnography is a testament to ways in which New York rooftops, for example, spaces often cluttered with garbage, bird droppings, and air-conditioning units, are being transformed into places made meaningful through enchanting interactions between humans and bees. These

Humanimalia: a journal of human/animal interface studies

Volume 8, Number 2 (Spring 2017) 
experiences often take the form of responsive human-insect gestures, which include affective signs and acts that are "not necessarily reciprocal, or fixed, but are emergent and in motion," such as humans speaking in hushed tones and moving slowly, or the sound of the hive when it is agitated or calm (Moore \& Kosut 89). They also take the shape of meditative, ritualistic experiences involving "echoes and reverberations" that are made and heard, but "not necessarily understood" (as Maeterlinck and von Frisch came to know without knowing). Moore and Kosut found that New York was suddenly filled with "dense places of intersection for humans and non-humans" (22), defined by an exposure to "the caress and sting of new experience" (Tuan 137). If attitudes towards bees, and the places where humans and bees interact, are to become definitive providing a new meaning for previously unused spaces - "they must be cultivated by practice, and the name for sustained, value-laden attitude practice is ritual" (Grimes 135). I suggest that urban spaces are being made meaningful (that is, in Tuan's terms, being turned into places) through the semiotic interactions that emerge between humans and bees in the form of rituals. I wager that one of the primary reasons why these interactions became a kind of interspecies ritual is the enchanting nature of the relationships that emerge there. By working through ideas of representational semiosis that move the concept of language beyond the human we can begin to understand beekeeping as a "responsive performance of mind/body and bee" that enacts the world, giving it definition and meaning (Moore \& Kosut 92).

Entanglements. Before analyzing some accounts of what I consider to be human/bee ritual, it is necessary to become open to what Eduardo Kohn has coined an "anthropology beyond the human," in which a recognition of the semiotic nature of life leads to the notion that humans and other animals are able to communicate through non-symbolic signals. Building upon 19th century meditations on semiotics by Charles Sanders Peirce, Kohn argues that non-symbolic representations in the form of icons (which embody likenesses, such as phasmatodea - the family of insects more commonly known as "stick insects") and indices (impacted by the objects they represent, such as when dark clouds suggest it might rain) are "more susceptible to the qualities, events, and patterns of the world" than symbolic reference (5). Beekeeping, as an interspecies ritual, is predicated on beekeepers becoming attuned to these other representational modes of communication. In Subversive Spiritualties: How Rituals Enact the World, anthropologist Frédérique Apffel-Marglin shows (in agreement with the work of Ronald Grimes) that "rituals are radically creative: they enact the world in concert with its humans, non-humans, and other-than-humans" (Apffel-Marglin 15). Of particular relevance here is the recognition that for all species "the world comes into being through intra-actions that typically take the form of rituals, those carefully orchestrated intra-actions meant to bring about a liveable world" (162). 
"Intra-action," as Karen Barad defines it, is "the mutual constitution of entangled agencies," where distinct (though relational and not absolute or pre-determined) agencies emerge through their intra-action (33). In other words, we become who we are by what we do with others. By using the prefix intra- instead of inter-, Barad signals that actions (or gestures) help to define creatures and the other entities around them, none of which are predetermined wholes interacting with one another. This is emblematic of the notion becoming with, where "the partners do not precede their relating" (Haraway 17). This action-oriented view of the world places movement and entanglement at the heart of life on Earth, recognizing that beings and entities do not occupy static spaces, but rather are made, nurtured, and woven through intra-actions that "propel the continuity of this common world" (Apffel-Marglin 162). Highlighting intra-activities between humans and horses, Maurstad et al. point to Barad's framework as a way of unpacking "intercorporeal moments of mutuality" between riders and their horses (324). We can, in this way, suggest that urban beekeeping has emerged as a particularly efficacious ritual, dense with intra-actions between humans and bees, intra-actions that happen through non-symbolic sensory representations such as particular sounds and movements, or gestures. These intra-actions bring the world into being and foster interspecies relationships that re-contextualize human/non-human hierarchies, where the agentic capacities of bees and humans are actualized "into an achieved continuity, into an achieved liveable and regenerated world" (Apffel-Marglin 163).

Awareness and attentiveness, which according to many of Moore \& Kosut's informants is heightened when in the presence of bees, are what Apffel-Marglin claims separate rituals from everyday actions. Ritual in this sense is the embodiment of enchantment. If the senses are attuned, tuned up, and recharged while one is enchanted by something, and if attentiveness and awareness define ritual practice, it becomes clear that the stories of urban beekeeping are contemporary accounts of interspecies ritual. In this light, the agency of both the bees and their human co-inhabitants become manifest, as urban beekeepers "develop routines that enhance their aptitude at hearing bees going slowly, being deliberate, breathing deeply, paying attention, and speaking in hushed tones" (Moore \& Kosut 98). Beekeeping, as a ritual marked by intra-actions between humans and bees, transforms urban locations into places of reverence made meaningful by the range of particular human and nonhuman relationships that emerge there. This way of thinking about relationality comports with Raffles's notion that places are "always active, always being made, always in process and practice," in a constant feedback loop of action and affect (183). It is through the intra-actions between humans and bees that "place, economy, and history are made" in unlikely urban

Humanimalia: a journal of human/animal interface studies

Volume 8, Number 2 (Spring 2017) 
locations. It is perhaps through reconfiguring urban beekeeping in this way that Moore \& Kosut came to consider bees as "cultured beings that traffic between worlds of the hive and of the urban landscape" (36).

This way of thinking about representation and relationality represents a critical rethinking of anthropology that moves beyond nature/culture and human/nonhuman dualisms to recognize that "animals and plants and places are people too," where people become open to the ecological and ethical possibilities that emerge through ritual enactment of the world together with other entities (Grimes 133). They also fundamentally re-think how realities are formed, by drawing attention to the different discursive-material realities that emerge through inter-species intra-actions. Paraphrasing Apffel-Marglin, neither waves nor particles are truer or more real than the other, but rather "constitute complementary moments of reality" (63; my emphasis). It is here that a reconfiguring of urban beekeeping as a ritualistic urban practice made meaningful by the semiotic intra-actions between humans and bees returns us neatly to Bennett's concept of enchantment, where ritual involves moving moments that often lie "buried in our innermost being" (Tuan 136).

Moving Moments. If we take seriously Grimes's claims that "everything depends on which people at which time in which specific place are engaging in which ways of ritualizing their relations with nature," and that "all social behaviour is not only ritualized but necessarily ritualized," we affirm that an anthropology beyond the human must encompass a renewed concept of "ritual performance [as] a primary way of becoming attuned to the planet," where "people behave more responsively, [and] thus more responsibly" with the animals, plants, and the places that surround them (133134). I would now like to place Bennett's model of enchantment within the conception of performative rituals promoted here by Apffel-Marglin and Grimes. I wish to come to terms with the "corporeal cues and intimate moments where beekeepers intersect with the hive, as not only vulnerable but also sensual bodies" (Moore \& Kosut 92). I wager that these intimate moments, moments of enchantment, moving moments, emerge within the intra-actions that occur between humans and bees in urban places made meaningful by those same intra-actions, and that the ritual performance of beekeeping involves resonances that extend beyond those moments and into our everyday lives.

I would like to take a close look at a passage by Meg Paska, a young beekeeper from New York whose insights feature heavily throughout Buzz:

I think I kind of understand why [people] are just blown away. I feel like for a long time, I had a lack of spirituality and this lack of God in my life 
in some way and I am not like a religious person at all, I don't subscribe to any sort of dogma. But after a while you start to feel a lack in your life. So when I started keeping bees, a light bulb went off and I felt sort of an immediate reverence for what goes on in the hive. Partially because it is still outside the realm of complete understanding. And I personally think that if there are magical creatures in the world, honeybees are those creatures. (Moore \& Kosut 103-104)

Paska recognizes that her immediate reverence for the hive might be due to the fact that she cannot completely understand what is happening in it, but that "knowability is based on intrinsic self-similarity" (Kohn 86), and that this semiotic knowing exists pervasively throughout all biological life. This may be reconceptualized as "the attribution by humans to non-humans of an interiority identical to their own," which "justifies extending a state of 'culture' to non-humans ... including ritualized conduct and deference to conventions" (Descola 129). Ritual, in this sense, can operate between species through their shared interiorities; that is, through their shared propensities to conduct a life intrinsically mediated by its semiotic constitution. It is "not through their souls that humans and non-humans differ but through their bodies." Developing an anthropology along these lines demands an acceptance that "there exist other kinds of thinking selves beyond the human" (Kohn 94). I suggest that the engagements now occurring between humans and bees, on the presupposition that humans have a duty to "save the bees" from ecological cataclysm (or at least to engage with them in more complementary ways), are motivating moving moments between humans and bees that require being attuned to the unexpected affinities we share with them, while also recognizing the differences that distinguish the many kinds of selves that populate the urban landscape.

Many urban beekeepers now ask bees to reciprocate with similar acknowledgements, by deciding not to suit up when they perform hive inspections, in order to connect more deeply with them:

I cannot tell you how every single one of your movements is very, very different when you've got no gloves, no veil, nothing. You just move in a different way, you think in a different way, your whole inner attitude becomes different, and then you realize "this is something to aim for ... in your relationships with bees." (Green \& Ginn 163)

Humanimalia: a journal of human/animal interface studies

Volume 8, Number 2 (Spring 2017) 
Claudia, a "severe German woman with wide acclaim in the field of natural beekeeping" (157), provides an excellent example of the ways in which "attentiveness to the points of view of other organisms ... allows us to create an affectionate relationship despite the fact that our worlds are so different" (Kohn 96). The affect that Claudia embodies suggests a consciousness, intention, and energy that emerge through "this kind of thick encounter" (Green \& Ginn 164). It is in this way that when we ask for recognition of the other, and make ourselves vulnerable to their sting, "we are not asking them to see us as we are," but rather asking them to see us as who we might become through our shared experiences and vulnerabilities. These entanglements are punctuated by enchanting moments that move us to transformation, and bring to the foreground the "ethical heart of alternative beekeeping," where what is at stake is not only "the beekeepers continued being in the world, the chance that these bee-lovers might leave the hive different from when they approached it," but the continued existence of the bees themselves.

Haraway provides a different example of enchantment as the shared experience between "play-constituted beings," where joy-enticing signals "usher us over the threshold into the world of meanings that do not mean what they seem to mean" (240). When Cayenne's (Haraway's now famous canine companion's) "entire bodily being glows as if in the phosphorescent ocean" after playing, it signals the

unexpected conjunctions and co-ordinations of creatively moving partners in play [that] take hold of both and put them into an open that feels something like an eternal present or suspension of time, a high of "getting it" together in action. (241)

Might this resemble the feeling of enchantment that beekeepers feel when, after years of training, they are able to tend their hives without any protective equipment, when they can "sidle up and partner with bees" to create a "type of collaborative free-form dance" (Moore \& Kosut 97)? Can we say that the bees are also enchanted by this communion because they are not stinging their human coinhabitants? Might this be what is happening when the tone of the buzz that a hive produces changes from the "A-sharp of a pissed off hive" to the "G-sharp of a happy hive"? (94).

Such encounters and moving moments, motivated by love, fear, sound, touch, and awareness, are examples of the way enchantment "hits one as if from out of the blue, without warning," and are reminders of the forces inherent in life itself (Bennett, Enchantment 169). They also embody the idea that an "ecological society must work directly on attitudes" which shape reactions to encounters with other ways of being 
(Morton 127). The locations of such encounters are not static, but moving. They encapsulate "a surprising encounter, a meeting with something that [we] did not expect and [are] not fully prepared to engage" that can help cultivate meaningful places out of urban spaces (Bennett, Vibrant 5). Furthermore, by inviting the "wild" into their backyards and onto their rooftops, humans are challenging the material and conceptual boundaries that exist between humans and non-humans. We can no longer speak of nature "out there," for "nature" is here. "Nature" is everywhere, and "nature" is nowhere. Humans are (part of) nature, and becoming attuned to the life cycle of bees and the way that they exist in the world is just one way which this is becoming realized. By inviting bees into cities, we are creating geographical, social, political, economic, and emotional places with them.

Toward an Anthropology of Bee-ing. I have covered a lot of ground; from placing enchantment alongside scientific enquiry, to cataclysm as a point of departure for a discussion of the transformation of urban spaces made meaningful through the ritual intra-actions that take place there, to the enchanting moments that animate our existence in a world that continues to surprise and inspire deep connections between all life forms. What this story presents then are ways to enjoy the world through becoming open to enchanting encounters with bees that might promote more complementary forms of inter-species engagement. Locating moments of enchantment within encounters with bees nudges us toward an understanding of the world in which our senses are more finely tuned, where non-symbolic communication is recognized to mean something. Enchantment is the moment that the world opens itself up to joyful new experiences marked by renewed enthusiasm for life, where language means more than words. We might, in this way, realize that what joins Maeterlinck, von Frisch, Paska, and the anthropologists, philosophers, geographers, and political theorists who study them, is that they have been struck by moments of enchantment that have shaped the way that they interact with the beings around them. They actualize into motion the idea that "affective fascination with the world thought to be worthy of it may help to ward off the existential resentment that plagues mortals, that is, the sense of victimization that recurrently descends upon the tragic (or absurd or incomplete) beings called human" (Bennett, Enchantment 12).

Morton suggests that "coexistence implies encounters between strange strangers," encounters that are "loving, risky and perverse," and that "the fact that the strange stranger might bite [or in this case sting] is the least of our worries" (80-81). I agree with the sentiment (that there are issues of much larger scales such as extinction and biodiversity loss at play); however, maybe Morton is wrong on one account, maybe the

Humanimalia: a journal of human/animal interface studies

Volume 8, Number 2 (Spring 2017) 
sting is where it all begins, as a warning that our movements and our gestures are not considered enough, that we are not engaging fully on the bees' terms. At the conclusion of Buzz, Moore \& Kosut offer two possible options for future relationships between humans and bees: radical disengagement and ethical engagement (216). This article has attempted to suggest ways in which we might be able to promote the latter. To become open to new experiences between species we need to "envision alternatives to the very lives we are living" (Peterson 239). We need to find ways of joining ideas and narratives of "biocultural hope" to practices and policies that manifest ethical engagement with other species (Kirksey, et al. 29). By finding new ways to think about, analyze, and practice urban beekeeping, we are providing just one example of how we might engage ethically with the rest of life on earth. As Anna Peterson states, "our world is full of wounds, human and nonhuman ... the point however is that we are not alone in it," and it is in "defending what we love against further wounding, [that] may well be the meaning of ethics" (op. cit., 239).

For Bennett, "ethics requires both a moral code (which condenses moral ideas and metaphysical assumptions into principles and rules) and an embodied sensibility (which organizes affects into a style and generates the impetus to enact the code)" (Enchantment 131). Now, if we can (brazenly) accept as a moral code the promotion of ecological awareness that seeks to minimize the harm and suffering caused to all lifeforms on earth (in this instance we have been concerned primarily with honeybees), might we also be able to accept enchantment as the embodied sensibility that generates the impetus to enact the code? If enchantment is the medium through which we are able to find complementary communion with other species, and given the importance of bees for life on Earth, then finding ways to promote enchanting moments between humans and bees must be ethical. Being struck by moving moments of enchantment propels us toward joy, and joy is, unlike enchantment, something that can be cultivated through practice. By practicing joy, we are practicing ethics. Bees are mirrors; by defending them, we are defending ourselves. But they are also windows; glimpses at a future made possible by a reconfiguring of our entanglements with them.

Mobilizing enchantment, ritual, science, and ecological awareness into one ethical framework that seeks to propel more prosperous engagements with bees is an endeavor that is worth attempting, if humans are to find ways to cultivate ecological praxis. By pointing toward an anthropology of bee-ing, I am suggesting ways of cultivating action that is thoughtful, and acting thoughtfully is to begin thinking in a way that promotes action with others that can flourish into the future. If anthropology is to find ways to account for the varied ways places acquire meaning through inter-species relationships, it must find ways to articulate and analyze the enchanting moments that promote 
ethical behavior between species. It is in this way that this paper promotes "forging concrete alliances among social and environmental worlds in the historical present, and caring for other beings and things," in ways that might generate "openings for more audacious hopes" (Kirksey, et al. 57). Ultimately, what is being suggested is a way to engage more openly, and more fully, in a world where coexistence (or a more astute understanding of existence) is a prerequisite for flourishing. The call to enchantment with bees, through the method of ritual as a way to conceptualize meaningful semiotic exchange, is at the heart of that suggestion. This will be not only an ethical engagement, the likes of which is called for by Moore \& Kosut, but a way of life that moves closer to realizing its joyous potential.

\section{Notes}

1. See Ransome, The Sacred Bee in Ancient Times and Folklore (1937); Buchmann, Letters From The Hive: An Intimate History of Bees, Honey, and Humankind (2006).

2. All foragers are female worker bees, accounting for the vast majority of honeybee populations.

3. "Living, throbbing confederations ... of humans and their (social, legal, linguistic) constructions" and "some very active and powerful non-humans: electrons, trees, wind, fire, electromagnetic fields", which enable "a theory of action and responsibility that crosses the human non-human divide" (Bennett, Vibrant Matter 24).

\section{Works Cited}

Apffel-Marglin, Frédérique. Subversive Spiritualties: How Rituals Enact the World. Oxford UP, 2013.

Barad, Karen. Meeting the Universe Halfway: Quantum Physics and the Entanglement of Matter and Meaning. Duke UP, 2007.

Bennett, Jane. The Enchantment of Modern Life. Princeton UP, 2001.

. Vibrant Matter: The Political Ecology of Things. Duke UP, 2010.

Buchmann, Stephen. Letters From The Hive: An Intimate History of Bees, Honey, and Humankind. Bantam, 2006.

Humanimalia: a journal of human/animal interface studies

Volume 8, Number 2 (Spring 2017) 
Cruikshank, Julie. Do Glaciers Listen: Local Knowledge, Colonial Encounters, and Social Imagination. U of British Columbia P, 2005.

De la Cadena, Marisol. Earth Beings: Ecologies of Practice Across Andean Worlds. Duke UP, 2015.

Descola, Phillippe. Beyond Nature and Culture. U of Chicago P , 2013.

Green, Kelsey, \& Franklin Ginn, "The Smell of Selfless Love: Sharing Vulnerability with Bees in Alternative Apiculture." Environmental Humanities 4 (2014): 149-170.

Grimes, Ronald R. Rite out of Place: Ritual, Media, and the Arts. Oxford UP, 2006.

Haraway, Donna J. When Species Meet. U of Minnesota P, 2008.

Jacobsen, Rowan. Fruitless Fall: The Collapse of the Honeybee and the Coming Agricultural Crisis. Bloomsbury, 2008.

Kimmerer, Robin Wall. Braiding Sweetgrass: Indigenous Wisdom, Scientific Knowledge, and the Teachings of Plants. Milkweed Editions, 2013.

Kirksey, Eben, Nicholas Shapiro, \& Maria Brodine. "Hope in Blasted Landscapes." The Multispecies Salon. Eben Kirksey, ed. Duke UP, 2014.

Kohn, Eduardo. "How Dogs Dream: Amazonian natures and the politics of transspecies engagement." American Ethnologist 34:1 (2007): 3-24.

. How Forests Think: Toward an Anthropology beyond the Human. U of California P, 2013.

Kosek, Jake. "Ecologies of Empire: On the New Uses of the Honeybee." Cultural Anthropology 25:4 (2010): 650-678.

Lindauer, Martin. Communication Among Social Bees. [1961]. Harvard UP, 2013.

Lockwood, Jeffrey. Six Legged Soldiers: Using Insects as Weapons of War. Oxford UP, 2009.

Maeterlinck, Maurice. The Life of the Bee. Ballantyne, Hanson \& Co., 1901. 
Mathews, Freya. 2001. "Planet Beehive." Australian Humanities Review 50 (May 2011).

Maurstad, Anita, Dona David, \& Sarah Cowles. "Co-being and intra-action in horsehuman relationships: a multi-species ethnography of be(com)ing human and be(com)ing horse." Social Anthropology 21.3 (2013): 322-335.

Moore, Lisa Jean, \& Mary Kosut. Buzz: Urban Beekeeping and the Power of the Bee. New York UP, 2013.

Morton, Timothy. The Ecological Thought. Harvard UP, 2010.

Nimmo, Richie. "The Bio-politics of Bees: Industrial Farming and Colony Collapse Disorder." Humanimalia 6.2 (Spring 2015): 2-20.

Peterson, Anna L. Being Human: Ethics, Environment, and Our Place in the World. U of California P, 2001.

Raffles, Hugh. Insectopedia. Pantheon, 2010.

Ransome, Hilda. The Sacred Bee in Ancient Times and Folklore. [1937]. Dover, 2004.

Safina, Carl. Beyond Words: What Animals Think and Feel. Henry Holt, 2015.

Tsing, Anna L. "Empowering Nature, or: Some Gleanings in Bee Culture." Naturalizing Power: Essays in Feminist Cultural Analysis. Ed. Sylvia Yanagisako \& Carol Delaney. Routledge, 1995. 113-43.

Tuan, Yi-Fu. Space and Place: The Perspective of Experience. U of Minnesota P, 1997.

Von Frisch, Karl. [1927]. The Dancing Bees: An Account of the Life and Senses of the Honey Bee. Methuen, 1954. 